\title{
Downregulating CREBBP inhibits proliferation and cell cycle progression and induces daunorubicin resistance in leukemia cells
}

\author{
CHAO GAO $^{1}$, SHU-GUANG LIU ${ }^{1}$, WEN-TING LU ${ }^{1}$, ZHI-XIA YUE ${ }^{1}$, XIAO-XI ZHAO ${ }^{1}$, \\ TIAN-YU XING ${ }^{1}$, ZHEN-PING CHEN ${ }^{1}$, HU-YONG ZHENG ${ }^{1}$ and ZHI-GANG LI $^{2}$ \\ ${ }^{1}$ Beijing Key Laboratory of Pediatric Hematology Oncology, National Key Discipline of Pediatrics \\ (Capital Medical University), Key Laboratory of Major Diseases in Children, Ministry of Education, \\ Hematology Oncology Center; ${ }^{2}$ Hematology and Oncology Laboratory, Beijing Pediatric Research Institute, \\ Beijing Children's Hospital, Capital Medical University, National Center for Children's Health, Beijing 100045, P.R. China
}

Received November 15, 2019; Accepted June 23, 2020

DOI: $10.3892 / \mathrm{mmr} .2020 .11347$

\begin{abstract}
Low expression levels of CREB-binding protein (CREBBP) have been demonstrated to be associated with high minimal residual disease at the end of induction therapy and adverse long-term outcomes in pediatric patients with acute lymphoblastic leukemia (ALL). However, the effect of low CREBBP expression on the prognosis of ALL has not yet been investigated. In the present study, CREBBP was downregulated and overexpressed in ALL cell lines (Jurkat and Reh). Sensitivity to chemotherapy and cell proliferation activity was determined via a Cell Counting Kit-8 assay. Cell cycle analysis was performed using flow cytometry. Immunofluorescence confocal microscopy and co-immunoprecipitation (Co-IP) assays were performed to determine the interaction between CREBBP and E2F transcription factor 3a (E2F3a). The binding of CREBBP to downstream gene caspase 8 associated protein 2 (CASP8AP2) promoters was assessed using a chromatin immunoprecipitation assay, and mRNA expression levels were detected via reverse transcription-quantitative PCR. Western blot analysis was performed to detect protein expression of CREBBP, E2F3a and CASP8AP2. Downregulation of
\end{abstract}

Correspondence to: Dr Hu-Yong Zheng, Beijing Key Laboratory of Pediatric Hematology Oncology, National Key Discipline of Pediatrics (Capital Medical University), Key Laboratory of Major Diseases in Children, Ministry of Education, Hematology Oncology Center, Beijing Children's Hospital, Capital Medical University, National Center for Children's Health, 56 Nanlishi Road, Beijing 100045, P.R. China

E-mail: zhenghuyong@vip.sina.com

Professor Zhi-Gang Li, Hematology and Oncology Laboratory, Beijing Pediatric Research Institute, Beijing Children's Hospital, Capital Medical University, National Center for Children's Health, 56 Nanlishi Road, Beijing 100045, P.R. China

E-mail: ericlzg70@hotmail.com

Key words: acute lymphoblastic leukemia, CREB-binding protein, E2F transcription factor 3, cell cycle
CREBBP increased the $\mathrm{IC}_{50}$ value of daunorubicin; however, no significant affects were observed on the $\mathrm{IC}_{50}$ values of vincristine and L-asparaginase. Furthermore, downregulation of CREBBP notably inhibited leukemia cell proliferation, accumulated cells in the $G_{0} / G_{1}$ phase and decreased cell proportions in the $\mathrm{S}$ and $\mathrm{G}_{2} / \mathrm{M}$ phases. Co-IP analysis demonstrated that CREBBP interacted with E2F3a, a transcription factor involved in $\mathrm{G}_{1} / \mathrm{S}$ transition. Immunofluorescence confocal microscopy indicated co-localization of CREBBP and E2F3a at the cell nucleus. Furthermore, E2F3a protein expression decreased in CREBBP RNA interference treated Jurkat and Reh cells. CASP8AP2, a target gene of E2F3a, was also identified to be a downstream gene of CREBBP. In addition, decreased $\mathrm{IC}_{50}$ value and cell proportions in the $\mathrm{G}_{0} / \mathrm{G}_{1}$ phase, accelerated cell proliferation and upregulated E2F3a and CASP8AP2 expression were exhibited in CREBBP overexpressed cells. Taken together, the results of the present study suggested that CREBBP downregulation affects proliferation and cell cycle progression in leukemia cells, potentially via the interaction and regulation of E2F3a, resulting in chemotherapy resistance. Thus, targeting CREBBP may be a therapeutic strategy for treating pediatric patients with ALL.

\section{Introduction}

Acute lymphoblastic leukemia (ALL) is a common malignancy in children worldwide. Genome-wide profiling studies, including DNA microarray and next generation sequencing have identified several genetic alterations associated with childhood ALL (1-3) CREB-binding protein (CREBBP) gene translocations have been observed in de novo ALL, and its mutations are enriched in relapsed pediatric patients with ALL and newly diagnosed patients with high hyperdiploid karyotype, with the potential of recurrence (4-6). It has been revealed that early loss of CREBBP confers murine malignant stem cell properties on lymphoid progenitors (7). Furthermore, a previous study reported that low CREBBP mRNA expression was associated with a high level of minimal residual disease (MRD) at the end of induction therapy and adverse long-term outcomes in pediatric patients with ALL, and suggested that the negative effect of CREBBP on prognosis may be improved 
with intensive chemotherapy (8). This clinical observation implies that CREBBP levels may influence the sensitivity of leukemia cells to chemotherapy.

The CREBBP gene encodes the cAMP response element binding-binding protein, a ubiquitously expressed transcriptional co-activator, which participates in regulating basic cellular processes and functions as a tumor suppressor in cell cycle control $(9,10)$. The interaction between CREBBP and E2F transcription factor 1 (E2F1), a member of the E2F family, has been associated with prognosis in non-small cell lung carcinomas (11). E2F family members are considered to function as transcription factors, and thus have critical roles in regulating cell cycle control (12). Gene microarray analyses have detected E2F3 mRNA expression in diagnostic samples of ALL, while other members are low or undetectable $(13,14)$. Furthermore, a previous study reported that overexpression of E2F3a in 697 and Reh cells accelerated cell proliferation, promoted leukemia cells to $S$ and $\mathrm{G}_{2} / \mathrm{M}$ phases and enhanced sensitivity to chemotherapeutic drugs (15).

Therefore, the present study aimed to investigate the influence of CREBBP on chemotherapy sensitivity in leukemia cells by regulating proliferation and cell cycle progression via interaction with and regulation of E2F3a. In addition, the present study suggested that targeting CREBBP may serve as a therapeutic strategy for pediatric patients with ALL.

\section{Materials and methods}

Cell culture. The human leukemia cell lines, Jurkat and Reh, were purchased from the Shanghai Institute of Biochemistry and Cell Biology, Chinese Academy of Sciences. Cells were maintained in RPMI-1640 (Thermo Fisher Scientific, Inc.) supplemented with 10\% FBS (cat. no. 16000036; Gibco; Thermo Fisher Scientific, Inc.) at $37^{\circ} \mathrm{C}$ in a $5 \% \mathrm{CO}_{2}$ atmosphere. Cell lines underwent DNA profiling of short tandem repeat analysis for authentication and mycoplasma contamination testing by Shanghai GeneChem Co., Ltd.

Downregulating CREBBP expression via short hairpin RNA (shRNA) transfection. The CREBBP lentivirus and scrambled shRNA control were purchased from Shanghai GeneChem Co., Ltd. The targeting RNAi sequences of sh-CREBBP and scrambled control were as follows: 5'-TATCAGAATAGGTATCATT-3' and 5'-TTCTCCGAA CGTGTCACGT-3', respectively. The shRNA-expressing recombinant plas- mids (hU6-MCS-Ubiquitin-EGFP-IRES-puromycin-GV248, Shanghai GeneChem Co., Ltd.; $20 \mu \mathrm{g}$ ), along with two helper plasmids, pGC-LV pHelper1.0 (Shanghai GeneChem Co., Ltd.; $15 \mu \mathrm{g}$ ) and 2.0 (Shanghai GeneChem Co., Ltd.; $10 \mu \mathrm{g}$ ) were transfected into 293 T cells (American Type Culture Collection) using transfection reagent $\left(2 \mathrm{M} \mathrm{CaCl}_{2}\right.$; Shanghai GeneChem Co., Ltd.). Cells were cultured to exponential phase in DMEM (Thermo Fisher Scientific, Inc.) supplemented with $10 \%$ FBS and transfected once they reached $70-80 \%$ confluence. Lentivirus was collected $48 \mathrm{~h}$ post-transfection via ultracentrifugation at $146,400 \times \mathrm{g}$ for $2 \mathrm{~h}$ at $4^{\circ} \mathrm{C}$. Jurkat and Reh cells were transduced at $37^{\circ} \mathrm{C}$ overnight with the concentrated virus in the presence of polybrene $(1 \mu \mathrm{g} / \mathrm{ml}$; Shanghai GeneChem Co., Ltd.), at a final multiplicity of infection value of 50 and 100, respectively. Subsequent experiments were performed $96 \mathrm{~h}$ after transfection.

Upregulating CREBBP expression via synergistic activation mediator (SAM). The CRISPR/defective Cas9 (dCas9) synergistic activation mediator system $(16,17)$ was used to overexpress CREBBP. dCas9-VP64-Puro (20 $\mu \mathrm{g}$; cat. no. GV418; Shanghai GeneChem Co., Ltd.) or single guide (sg) RNA-MS2-P65-HSF1-Neo-GV468 lentiviral vectors $(20 \mu \mathrm{g})$, along with pGC-LV pHelper1.0 $(15 \mu \mathrm{g})$ and $2.0(10 \mu \mathrm{g})$ were transfected into $293 \mathrm{~T}$ cells (confluency, 70-80\%), using transfection reagent $\left(2 \mathrm{M} \mathrm{CaCl}_{2}\right.$; Shanghai GeneChem Co., Ltd.). Lentivirus was collected $48 \mathrm{~h}$ post-transfection via ultracentrifugation at $146,400 \times \mathrm{g}$ for $2 \mathrm{~h}$ at $4^{\circ} \mathrm{C}$. Stable Jurkat and Reh cells were generated by infecting with dCas9-VP64-Puro lentivirus at a final multiplicity of infection value of 50 and 100 , and screened with puromycin dihydrochloride $(3 \mu \mathrm{g} / \mathrm{ml}$; Thermo Fisher Scientific, Inc.). Subsequently, the stable cell lines were infected with CREBBP sgRNA or mock vector lentivirus (cat. no. CON275; Shanghai GeneChem Co., Ltd.). The sgRNA sequence targeting the promoter of CREBBP was designed by www.rgenome.net/cas-designer and the matching sequence for CREBBP was 5'-CCACTTAATGAATTCGCTCG-3'. At $96 \mathrm{~h}$ post-transfection, subsequent experiments were performed.

Reverse transcription-quantitative (RT-q)PCR. Total RNA from Jurkat and Reh cells was extracted using TRIzol ${ }^{\circledR}$ reagent (Thermo Fisher Scientific, Inc.). Total RNA (1 $\mu \mathrm{g})$ was incubated with random hexamers (Promega Corporation) at $70^{\circ} \mathrm{C}$ for $5 \mathrm{~min}$ and then reverse transcribed into cDNA at $37^{\circ} \mathrm{C}$ for $1 \mathrm{~h}$ using M-MLV Reverse Transcriptase and buffer (Promega Corporation) with dNTPs (2.5 mM; Promega Corporation). qPCR was performed in triplicate using TaqMan Gene Expression Master Mix (cat. no. 4369016; Thermo Fisher Scientific, Inc.) and ViiA 7 system (Thermo Fisher Scientific, Inc.). The Abelson (ABL) gene was used as an internal control gene. The primers and probes were synthesized by Sangon Biotech Co., Ltd. The primers used for mRNA detection were as follows: Caspase 8 associated protein 2 (CASP8AP2) forward, 5'-CACTTGCCACTTCTA CAAGTC-3' and reverse, 5'-TGGCGGCTAAATATGCAA ATG-3'; ABL forward, 5'-CCTTCAGCGGCCAGTAGC-3' and reverse, 5'-GGACACAGGCCCATGGTAC-3'. The probes were 5'-FAM-TGTCAGAAAAGAGGGCCATCA TTTAAA-TAMRA-3' and 5'-FAM-CCATTTTTGGTTTGG GCTTCACACCATT-TAMRA-3' for CASP8AP2 and ABL, respectively. The following thermocycling conditions were used for qPCR: Pre-denaturation at $95^{\circ} \mathrm{C}$ for $10 \mathrm{~min}$; followed by 40 cycles of denaturation at $95^{\circ} \mathrm{C}$ for $15 \mathrm{sec}$ and annealing at $60^{\circ} \mathrm{C}$ for $1 \mathrm{~min}$. The relative expression of CASP8AP2 was calculated using the $2^{-\triangle \Delta C q}$ method (18) and is shown as fold changes, as compared with control group. Gene transcription levels were normalized to that of $\mathrm{ABL}$ and set to 1 in the control group.

Western blotting. Protein lysates were prepared using RIPA lysis buffer (Thermo Fisher Scientific, Inc.). Protein concentration was determined using the Pierce bicinchoninic acid protein assay (Thermo Fisher Scientific, Inc.), and $50 \mu \mathrm{g}$ protein/lane was separated on $4-15 \%$ Tris-glycine precast 
gels (Bio-Rad Laboratories, Inc.). Proteins were transferred onto a PVDF membranes and blocked with 5\% non-fat milk at $25^{\circ} \mathrm{C}$ for $1 \mathrm{~h}$, prior to incubation with primary antibodies against CREBBP (cat. no. sc-369; 1:500; Santa Cruz Biotechnology, Inc.), E2F3 (cat. no. sc-878; 1:500; Santa Cruz Biotechnology, Inc.), CASP8AP2 (cat. no. YT6423; 1:500; ImmunoWay Biotechnology, Inc.) or GAPDH (cat. no. 51332; 1:2,000; Cell Signaling Technology, Inc.) overnight at $4^{\circ} \mathrm{C}$. Membranes were washed three times for 10 min with TBST buffer (cat. no. B1009; Applygen Technologies, Inc.) and subsequently incubated with horseradish peroxidase-conjugated goat anti-rabbit IgG or anti-mouse secondary antibody (cat. nos. 7074 and 7076, 1:5,000; Cell Signaling Technology, Inc.) for $1 \mathrm{~h}$ at room temperature. Blots were re-washed and signals were visualized with super enhanced chemiluminescence (ECL) detection reagent (Applygen Technologies, Inc.), then imaged using Amersham Imager 600 (Cytiva) and analyzed with ImageQuant ${ }^{\mathrm{TM}} \mathrm{TL}$ software (version 7.0; Cytiva).

In vitro drug sensitivity assay. The in vitro sensitivity of daunorubicin (DNR; Melone Pharmaceutical Co., Ltd), vincristine (VCR; Melone Pharmaceutical Co., Ltd) and L-asparaginase (L-ASP; Kyowa Hakko Kirin Co., Ltd.)-transfected Jurkat and Reh cells was determined via the Cell Counting Kit-8 (CCK-8) assay. Transfected cells were seeded into a 96-well plate $(\sim 10,000$ cells/well) and treated with or without gradient concentrations of each drug at $37^{\circ} \mathrm{C}$ for $24 \mathrm{~h}$. The gradient concentrations for DNR, VCR and L-ASP were $0.001-1000 \mu \mathrm{M}$, $0.001-1000 \mu \mathrm{M}$ and $0.001-10 \mathrm{U} / \mathrm{ml}$, respectively. All samples were assessed in triplicate. After $24 \mathrm{~h}, \mathrm{CCK}-8$ reagent $(10 \mu \mathrm{l}$ per well; Applygen Technologies, Inc.) was added to each well and incubated at $37^{\circ} \mathrm{C}$ for $2 \mathrm{~h}$. Following the CCK-8 incubation, the plates were analyzed at a wavelength of $450 \mathrm{~nm}\left(\mathrm{~A}_{450}\right)$ using a microplate reader (Thermo Fisher Scientific, Inc.). The inhibitory rate at each concentration was calculated as follows: [1- $\left(\mathrm{A}_{450}\right.$ of DNR exposed well/ $\mathrm{A}_{450}$ of negative control well $\left.)\right]$ $\mathrm{x} 100 \%$. The $\mathrm{IC}_{50}$ value was calculated using the curve fitting method (19), in order to determine cellular sensitivity of each drug.

Cell proliferation assay and cell cycle analysis. CCK-8 was used to assess cell viability. Cells were seeded into a 96-well plate $\left(2,000\right.$ cells/well) and incubated at $37^{\circ} \mathrm{C}$ in a humidified atmosphere containing $5 \% \mathrm{CO}_{2}$ for 24,48 or $72 \mathrm{~h}$, respectively. CCK-8 (10 $\mu \mathrm{l}$ per well; Applygen Technologies, Inc.) was subsequently added to the well at $0,24,48$ and $72 \mathrm{~h}$, respectively, and incubated for $2 \mathrm{~h}$ at $37^{\circ} \mathrm{C}$. The plates were analyzed at a wavelength $\mathrm{A}_{450}$ using a microplate reader, and a spectrophotometer was used to measure the optical density.

Flow cytometric analysis was performed to determine changes in cell cycle distribution. Harvested cells were washed twice with PBS, fixed with $70 \%$ cold ethanol overnight at $4^{\circ} \mathrm{C}$ and digested with RNaseA (Nanjing KeyGen Biotech Co., Ltd.) at $37^{\circ} \mathrm{C}$ for $30 \mathrm{~min}$. Cells were subsequently stained with $400 \mu \mathrm{l}$ propidium iodide (Nanjing KeyGen Biotech Co., Ltd.) and incubated at room temperature for $30 \mathrm{~min}$ and the cell cycle phase fractions were determined via flow cytometry (Canto II, BD Biosciences) using Modfit LT software (version 3.1; Verity Software House, Inc.).
Immunofluorescence confocal microscopy. Transfected cells (Jurkat or Reh) were seeded onto poly-L-lysine (cat. no. P8120; Beijing Solarbio Science \& Technology Co., Ltd.) coated glass slides $(20,000$ cells/slide). Cells were fixed with $4 \%$ paraformaldehyde (Sigma-Aldrich; Merck KGaA) for $15 \mathrm{~min}$ at room temperature, washed three times with PBS for $5 \mathrm{~min}$, permeabilized with $0.1 \%$ Triton $\mathrm{X}-100$ for $10 \mathrm{~min}$ and blocked with $2 \%$ BSA (cat. no. 0332; Amresco, LLC) for $1 \mathrm{~h}$ at room temperature. Subsequently, cells were incubated with primary antibodies against CREBBP (cat. no. sc-369; 1:500; Santa Cruz Biotechnology, Inc.) and E2F3 (cat. no. sc-56665; 1:500; Santa Cruz Biotechnology, Inc.) overnight at $4^{\circ} \mathrm{C}$. Following the primary incubation, cells were incubated with goat anti-mouse (1:2,000; cat. no. A32727) and goat anti-rabbit (1:2,000; cat. no. A32731; both from Thermo Fisher Scientific, Inc.) secondary antibodies at room temperature for $1 \mathrm{~h}$. The nuclei were stained with DAPI (100 ng/ml; cat. no. ZLI-9557; OriGene Technologies, Inc.) at room temperature for $15 \mathrm{~min}$ and fluorescence images were observed under a spinning disk confocal microscope (PerkinElmer, Inc.), with a x100 oil-immersion objective lens.

Co-immunoprecipitation (Co-IP) assay. Cells were collected and lysed using Co-RIPA buffer (Applygen Technologies, Inc.) on ice for $30 \mathrm{~min}$. Cell lysates were pre-cleared with protein $\mathrm{A} / \mathrm{G}-\mathrm{Sepharose}$ beads (EMD Millipore) at $4^{\circ} \mathrm{C}$ for $1 \mathrm{~h}$, prior to immunoprecipitation with primary antibodies against CREBBP (4 $\mu \mathrm{g} / \mathrm{ml}$; cat. no. sc-7300), E2F3 $(4 \mu \mathrm{g} / \mathrm{ml}$; cat. no. sc-56665) and $\mathrm{IgG}(4 \mu \mathrm{g} / \mathrm{ml}$; cat. no. sc-2025; all from Santa Cruz Biotechnology, Inc.) overnight at $4^{\circ} \mathrm{C}$, with gentle rotation in a rotation mixer (WH-986; Kylin-Bell Lab Instruments Co., Ltd.). The protein-antibody complexes were incubated with protein A/G-Sepharose beads for $4 \mathrm{~h}$ at $4^{\circ} \mathrm{C}$, with rotation and then centrifuged at $800 \mathrm{x}$ g for $5 \mathrm{~min}$ at $4^{\circ} \mathrm{C}$. Subsequently, the beads were washed three times with cold Co-RIPA buffer and the bound proteins were separated via 4-15\% SDS-PAGE. The desired co-immunoprecipitated proteins were detected using the Clean-Blot IP Detection kit (Thermo Fisher Scientific, Inc.). The antibodies used in the immunoblotting detection were the same as those used in western blot analysis.

Chromatin immunoprecipitation (ChIP) assay. Jurkat and Reh cells were used for ChIP analysis using the EZ-ChIP kit (EMD Millipore), according to manufacturer's protocol. Each ChIP reaction contained chromatin collected from $1 \times 10^{7}$ cells and $2 \mu \mathrm{g}$ anti-CREBBP antibody (cat. no. sc-7300x; 1:500; Santa Cruz Biotechnology, Inc.) or normal negative control IgG (cat. no. sc-2025; 1:500; Santa Cruz, Biotechnology, Inc.). Following immunoprecipitation overnight at $4^{\circ} \mathrm{C}$, the binding sites (revealed by www.cbil.upenn.edu/tess) of CREBBP to target CASP8AP2 promoters were analyzed via PCR. The enriched DNA binding CREBBP from Jurkat and Reh cells was amplified using Gotaq DNA polymerase (Promega Corporation). The amplification conditions were as follows: Pre-denaturation at $95^{\circ} \mathrm{C}$ for $3 \mathrm{~min}$; followed by 40 cycles of denaturation at $95^{\circ} \mathrm{C}$ for $20 \mathrm{sec}$, annealing at $60^{\circ} \mathrm{C}$ for $30 \mathrm{sec}$, and extension at $72^{\circ} \mathrm{C}$ for $10 \mathrm{~min}$. The following Primer sequences were used in the ChIP assay to detect the CASP8AP2 promoter: Forward, 5'-ACTCCAGTTTGG 
A

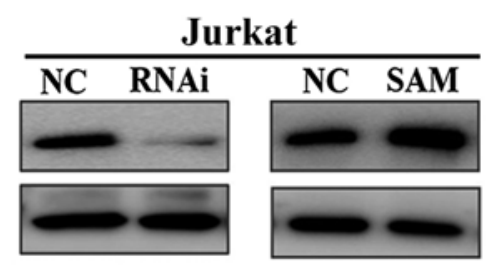

Reh

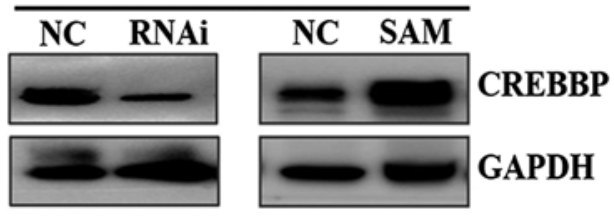

B

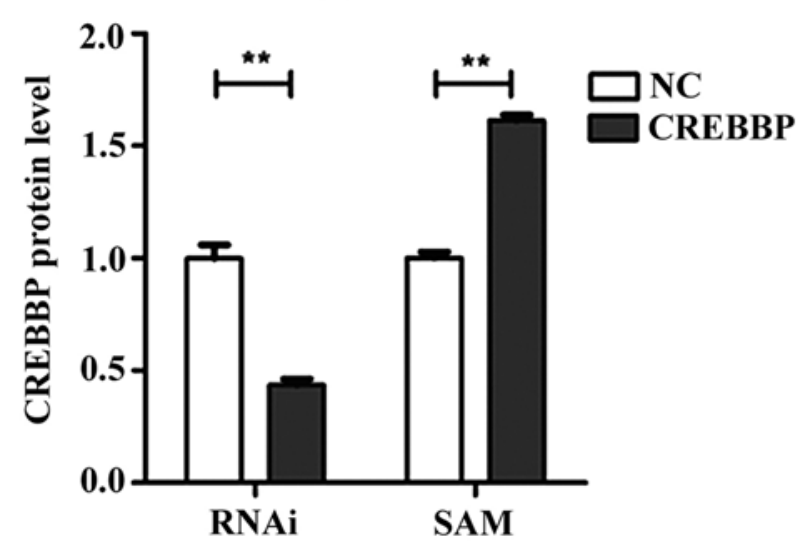

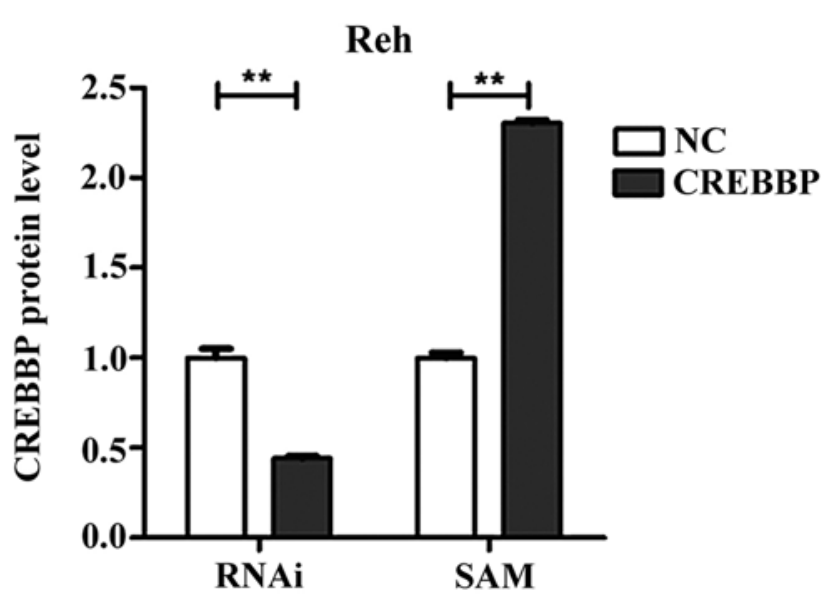

Figure 1. Downregulation and overexpression of CREBBP in Jurkat and Reh cells. (A) Western blot analysis of CREBBP protein expression in Jurkat and Reh cells following RNAi or SAM treatment. GAPDH was used as the internal loading control. (B) Relative CREBBP protein expression in Jurkat and Reh cells following downregulation or overexpression. Data are presented as the mean \pm standard error of the mean $(n=3)$. ${ }^{* *} \mathrm{P}<0.01$. CREBBP, CREB-binding protein; RNAi, RNA interference; SAM, synergistic activation mediator; NC, negative control.

CGCCAACC-3' and reverse, 5'-GACAACCCGGTTCCTTT CTG-3'.

Statistical analysis. $\mathrm{IC}_{50}$ curves were plotted and values were determined via the non-linear curve fit of $Y=100 /\left(1+10^{\text {(LogIC50-X) }}\right.$ x HillSlope), using GraphPad Prism software 5.0 (GraphPad Software, Inc.). Differences between $\mathrm{IC}_{50}$ values for each chemotherapeutic drug, with or without affecting CREBBP expression, were compared using the extra-sum-of-squares F test within GraphPad Prism. SPSS software 16.0 (SPSS, Inc.) was used for comparison of the gene or protein expression level, cell counts and cell cycle fraction, and two-tailed independent-samples t-test was used to compare differences between two groups. Data are presented as the mean \pm standard error of the mean, and all experiments were performed in triplicate. $\mathrm{P}<0.05$ was considered to indicate a statistically significant difference.

\section{Results}

Effect of CREBBP on drug sensitivity in leukemia cells. CREBBP was successfully downregulated $(\mathrm{P}<0.01$ and $\mathrm{P}<0.01$ for Jurkat and Reh, respectively) and overexpressed $(\mathrm{P}<0.01$ and $\mathrm{P}<0.01$ for Jurkat and Reh, respectively) in Jurkat and Reh cells following treatment with RNAi and SAM for $96 \mathrm{~h}$, respectively (Fig. 1). The effect of CREBBP on sensitivity of leukemia cells to DNR, VCR and L-ASP was assessed. The results demonstrated that the $\mathrm{IC}_{50}$ values of DNR were significantly increased in RNAi-treated Jurkat cells $(0.04 \mu \mathrm{M}$ vs. $0.11 \mu \mathrm{M} ; \mathrm{P}=0.01$; Fig. $2 \mathrm{~A})$, and significantly decreased in SAM-treated Jurkat cells $(0.13 \mu \mathrm{M}$ vs. $0.07 \mu \mathrm{M} ; \mathrm{P}<0.01$;
Fig. 2B). Similar effects were observed in RNAi-treated Reh cells $(0.53 \mu \mathrm{M}$ vs. $1.59 \mu \mathrm{M} ; \mathrm{P}<0.01$; Fig. $2 \mathrm{C})$ and SAM-treated Reh cells $(0.27 \mu \mathrm{M}$ vs. $0.12 \mu \mathrm{M} ; \mathrm{P}=0.04$; Fig. 2D). However, no significant effects were observed between the $\mathrm{IC}_{50}$ values of VCR and L-ASP and CREBBP expression (Figs. S1 and S2). Taken together, these results suggested that leukemia cells with low CREBBP expression may be more resistant to DNR.

Effect of CREBBP on cell proliferation and cell cycle progression. The CCK-8 assay demonstrated that downregulation of CREBBP significantly inhibited cell proliferation at $24 \mathrm{~h}(\mathrm{P}<0.01$ and $\mathrm{P}<0.01$ for Jurkat and Reh, respectively), $48 \mathrm{~h}(\mathrm{P}<0.01$ and $\mathrm{P}<0.01$ for Jurkat and Reh, respectively) and $72 \mathrm{~h}(\mathrm{P}<0.01$ and $\mathrm{P}<0.01$ for Jurkat and Reh, respectively) (Fig. 3A and C), whereas overexpression of CREBBP significantly promoted proliferation of Jurkat $(\mathrm{P}=0.04$ and $\mathrm{P}=0.04$ for 48 and $72 \mathrm{~h}$, respectively) and Reh $(\mathrm{P}<0.01, \mathrm{P}=0.04$ and $\mathrm{P}=0.03$ for 24,48 and $72 \mathrm{~h}$, respectively) cells (Fig. 3B and D). Furthermore, downregulation of CREBBP arrested cell cycle in the $\mathrm{G}_{0} / \mathrm{G}_{1}$ phase, while overexpression of CREBBP decreased the proportion of cells in the $\mathrm{G}_{0} / \mathrm{G}_{1}$ phase (Fig. 4). Furthermore, the proportion of $\mathrm{G}_{2} / \mathrm{M}$ cells was decreased in CREBBP downregulation Jurkat $(\mathrm{P}<0.01)$ and the proportion of $\mathrm{S}$ phase cells was increased in CREBBP overexpression Reh $(\mathrm{P}=0.04)$. No significant effect on $\mathrm{S}$ phase in CREBBP downregulation Jurkat and Reh cells and $\mathrm{G}_{2} / \mathrm{M}$ phase in CREBBP overexpression Jurkat and Reh cells was observed. Overall, these results indicated that CREBBP plays an essential role in $\mathrm{G}_{1} / \mathrm{S}$ transition and cell proliferation.

CREBBP interacts and regulates the transcription factor $E 2 F 3 a$. The E2F transcription factor family serves a key 
A

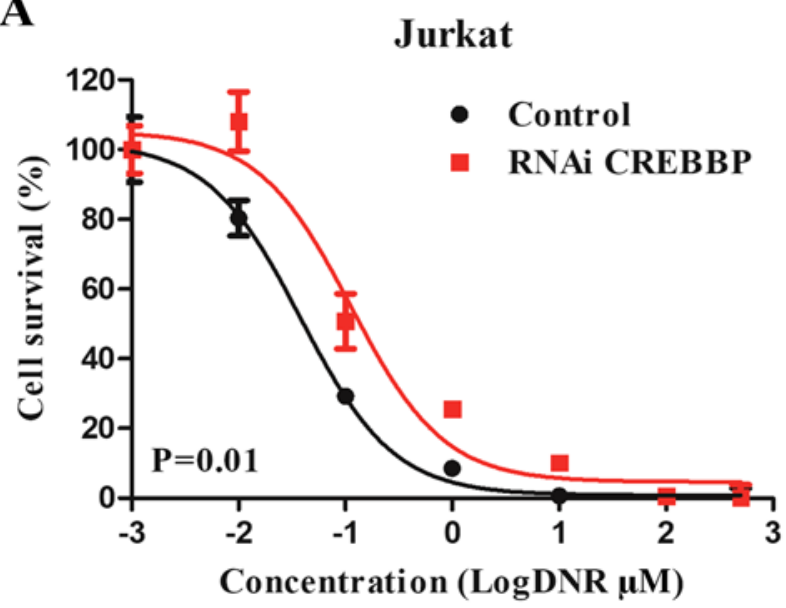

C

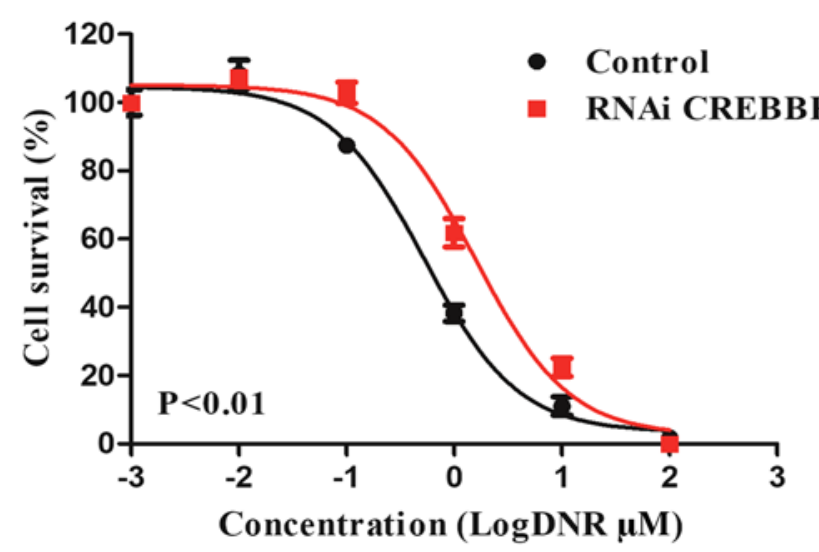

B

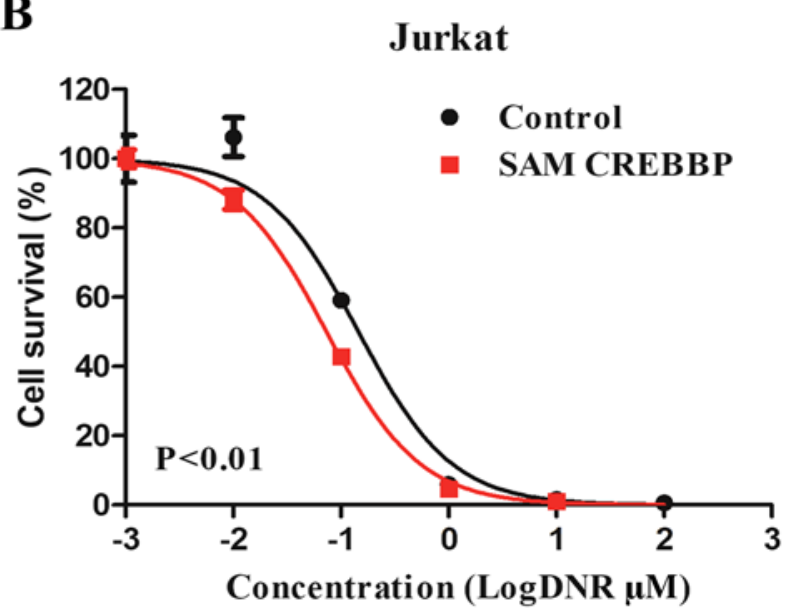

D

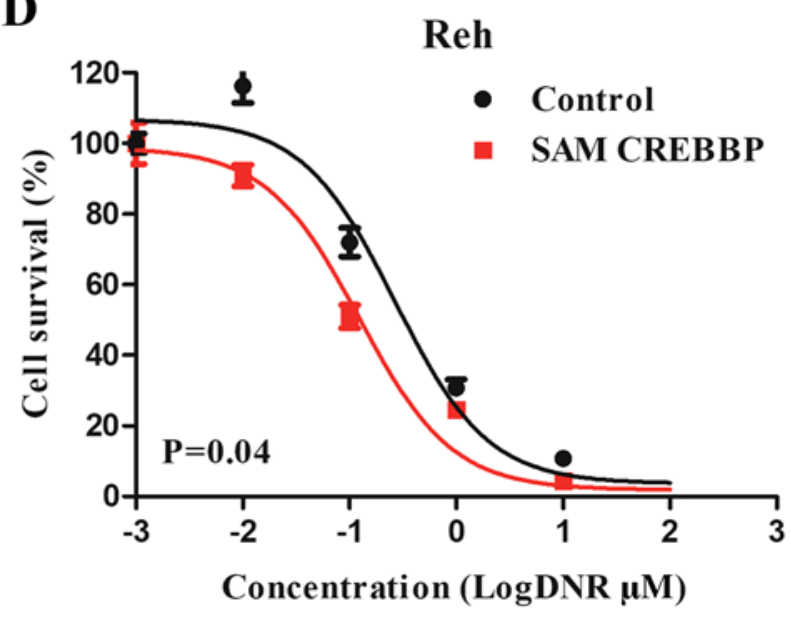

Figure 2. Effect of DNR with different CREBBP expression levels on Jurkat and Reh cell sensitivity. (A) Sensitivity of Jurkat cells to DNR decreased following downregulation of CREBBP and (B) increased following overexpression of CREBBP. (C) Sensitivity of Reh cells to DNR decreased following downregulation of CREBBP and (D) increased following overexpression of CREBBP. The extra-sum-of-squares $\mathrm{F}$ test was used to compare the $\mathrm{IC}_{50}$ values. Data are presented as the mean \pm standard error of the mean $(n=3)$. DNR, daunorubicin; RNAi, RNA interference; SAM, synergistic activation mediator; CREBBP, CREB-binding protein.

role in cell cycle regulation (12). Our previous study reported that overexpression of E2F3a enhances the sensitivity of 697 and Reh cells to DNR (15). In the present study, immunofluorescence confocal microscopy analysis demonstrated that CREBBP and E2F3a co-localized in the nuclei of Jurkat and Reh cells (Fig. 5A). The interaction between CREBBP and E2F3a was confirmed via Co-IP analysis (Fig. 5B). Furthermore, western blot analysis demonstrated that E2F3a protein expression was associated with CREBBP expression (Fig. 5C and D). E2F3a was downregulated in RNAi-treated Jurkat and Reh cells $(\mathrm{P}<0.01$ and $\mathrm{P}<0.01$ for Jurkat and Reh, respectively), and upregulated in SAM-treated Jurkat and Reh cells $(\mathrm{P}<0.01$ and $\mathrm{P}<0.01$ for Jurkat and Reh, respectively) (Fig. 5C and D). Collectively, these results suggested that CREBBP may influence the cell cycle via the interaction and regulation of $\mathrm{E} 2 \mathrm{~F} 3 \mathrm{a}$.

Identification of CASP8AP2 as a downstream gene of $C R E B B P$. Our previous study revealed that E2F3a activates the transcription of CASP8AP2 (15). Since CREBBP was indicated to interact with E2F3a, the role of CREBBP in the regulation of CASP8AP2 expression in leukemia cells was further investigated. Bioinformatics analysis revealed two CREBBP putative binding sites ( $\mathrm{C} 1$ and $\mathrm{C} 2)$ within the CASP8AP2 promoter region (-120 bp and $-70 \mathrm{bp})$, based on Homo sapiens chromosome 6, GRCh38 (Fig. 6A). ChIP assay identified CREBBP binding to CASP8AP2 promoters that contained these two binding sites in Jurkat and Reh cells (Fig. 6A). Furthermore, CASP8AP2 mRNA expression decreased following downregulation and increased following overexpression of CREBBP in Jurkat and Reh cells (Fig. 6B). Similarly, CASP8AP2 protein expression was also affected in relation to CREBBP expression (Fig. 6C and D). Overall, these results indicated that $\mathrm{CREBBP}$ and $\mathrm{E} 2 \mathrm{~F} 3 \mathrm{a}$ regulate CASP8AP2 expression.

\section{Discussion}

A previous study reported that patients with low CREBBP expression are associated with high levels of MRD following induction therapy, as well as inferior long-term outcomes in pediatric patients with ALL (8). However, the molecular mechanisms associated with low CREBBP on prognosis have not yet been fully investigated. Furthermore, it has been shown 
A

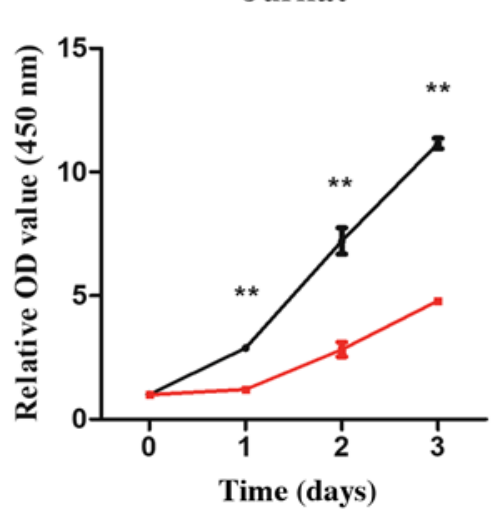

C

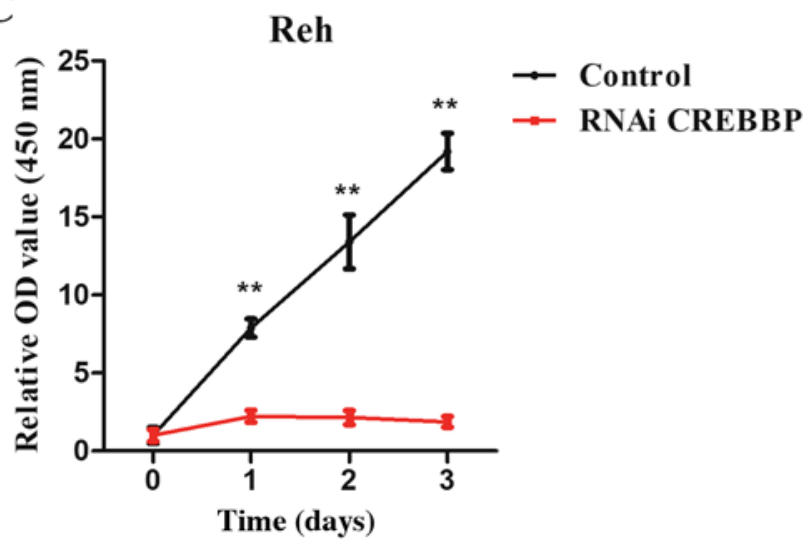

B
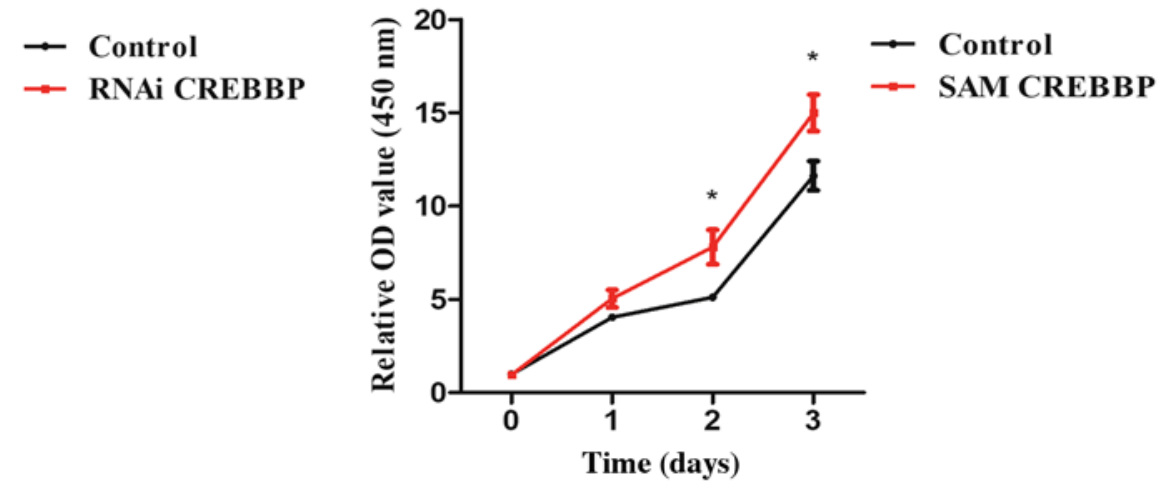

D

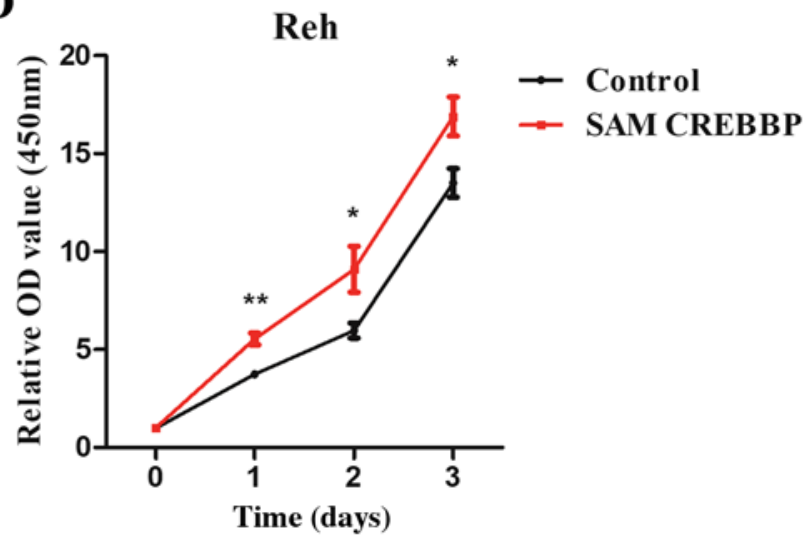

Figure 3. Effect of different CREBBP expression levels on Jurkat and Reh cell proliferation. (A) Downregulation of CREBBP inhibited Jurkat cell proliferation. (B) Overexpression of CREBBP accelerated Jurkat cell proliferation. (C) Downregulation of CREBBP inhibited Reh cell proliferation. (D) Overexpression of CREBBP accelerated Reh cell proliferation. Data are presented as the mean \pm standard error of the mean $(\mathrm{n}=3)$. ${ }^{*} \mathrm{P}<0.05$; ${ }^{* *} \mathrm{P}<0.01$ vs. control. CREBBP, CREB-binding protein; RNAi, RNA interference; SAM, synergistic activation mediator; OD, optical density.

that the prognosis of patients with low CREBBP expression who have received an intermediate risk regimen improves compared with those taking standard risk regimen (8). Thus, it was hypothesized that CREBBP expression may affect the sensitivity of leukemia cells to chemotherapy. The present study assessed the $\mathrm{IC}_{50}$ values of key chemotherapeutic drugs (DNR, VCR and L-ASP) used for induction therapy in ALL cell lines (Jurkat and Reh), with varying levels of CREBBP expression. The results demonstrated that downregulation of CREBBP decreased the sensitivity of Jurkat and Reh cells to DNR, while overexpression of CREBBP benefited DNR with regards to leukemia cell death. However, CREBBP expression levels did not affect sensitivity to VCR and L-ASP. VCR primarily exerts its antitumor effect by blocking the cell cycle at the mitotic phase, thus inhibiting the polymerization of tubulin and the formation of spindle microtubules (20). L-ASP degrades and depletes asparagine in the blood and starves leukemia cells (21). DNR is an anthracycline chemotherapeutic drug that inhibits DNA and DNA-dependent RNA synthesis (22), and has been extensively used in the treatment of leukemia. Moreover, DNR is a non-specific cell cycle agent, and thus exerts cytotoxic effects at every phase of the cell cycle, including $G_{0}, G_{1}, S, G_{2}$ and $M(23)$. The results of the present study suggested that low CREBBP expression potentially resulted in DNR chemoresistance via regulation of cell cycle progression.
It has been reported that tumors with low proliferation rates are insensitive to chemotherapy as most of the cells are non-proliferative (24). The present results demonstrated that downregulation of CREBBP significantly inhibited the proliferation of Jurkat and Reh cells, whereas overexpression of CREBBP significantly accelerated cell proliferation. Furthermore, downregulation of CREBBP was significantly associated with accumulation of Jurkat and Reh cells at the $\mathrm{G}_{0} / \mathrm{G}_{1}$ phase. These results suggested that CREBBP may affect drug sensitivity via proliferation and cell cycle progression. Previous studies have revealed the key role of CREBBP in promoting cell proliferation and regulating cell cycle progression $(25,26)$. For example, depletion of CREBBP has been reported to limit $S$ phase entry, a phenomenon that can be reversed by overexpressing CREBBP (26), which is consistent with the results of the present study.

CREBBP functions as a coactivator, which regulates cell cycle progression partly through its influence on transcription (27). The E2F transcription factor family is involved in the regulation of gene expression, which is central for $G_{1} / S$ transition (28-30). CREBBP may interact and acetylate E2F family proteins to activate target gene transcription $(31,32)$. Gene microarray analysis identified E2F3 mRNA expression in a diagnostic sample from patients with ALL, while other members were low or undetectable $(13,14)$. There are two isoforms of E2F3, E2F3a and E2F3b. E2F3a is only 
A

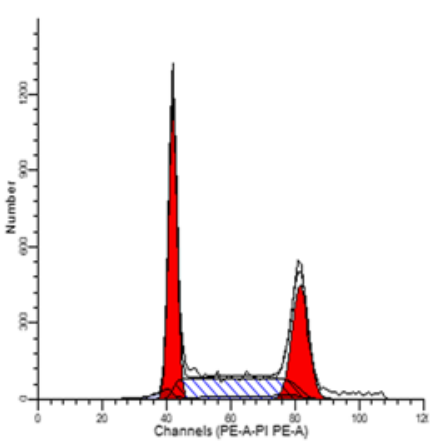

D

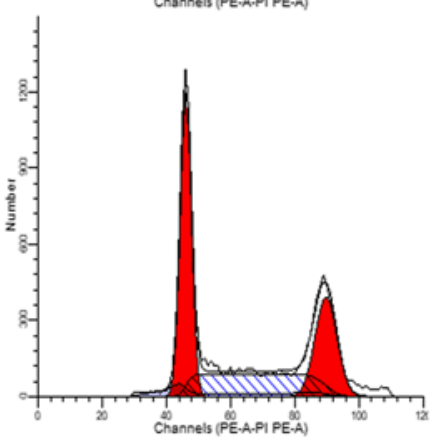

G

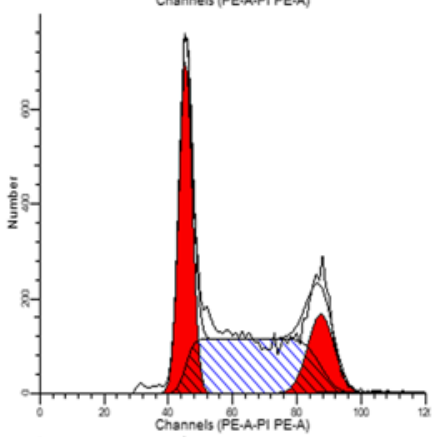

J

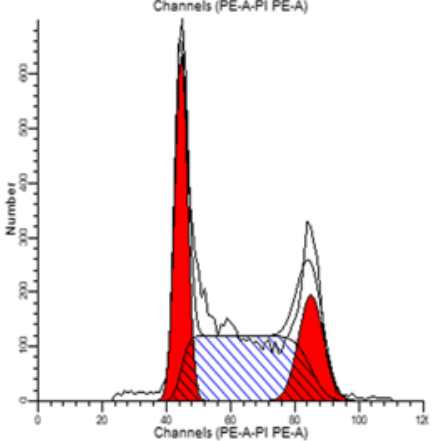

B

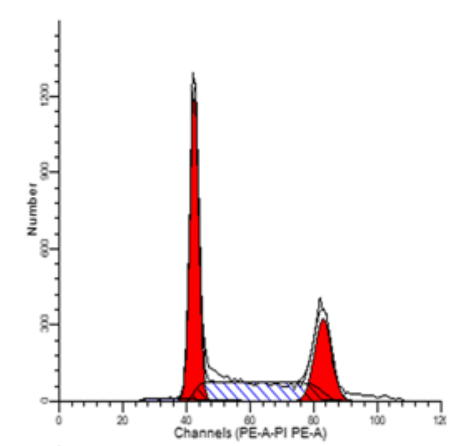

E

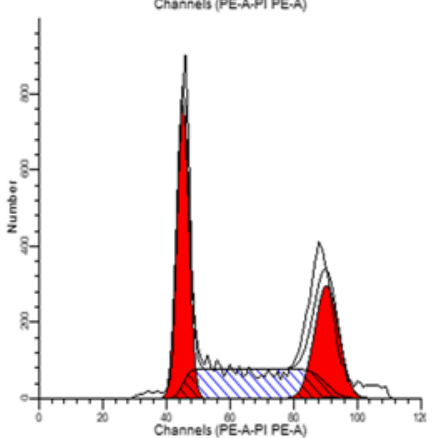

H

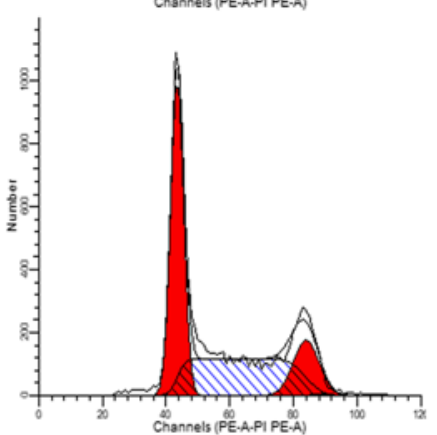

K

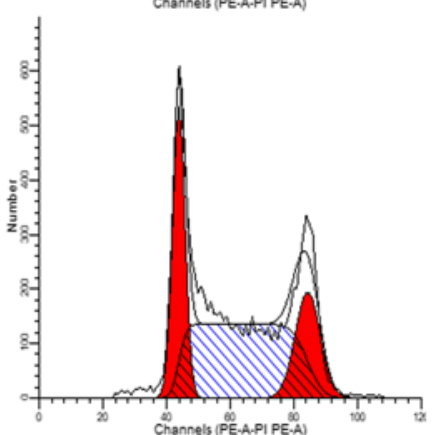

C

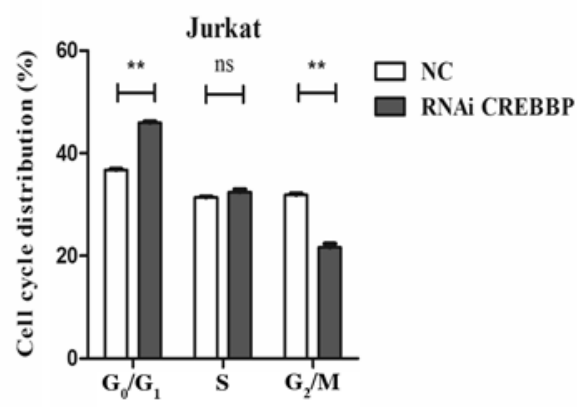

F

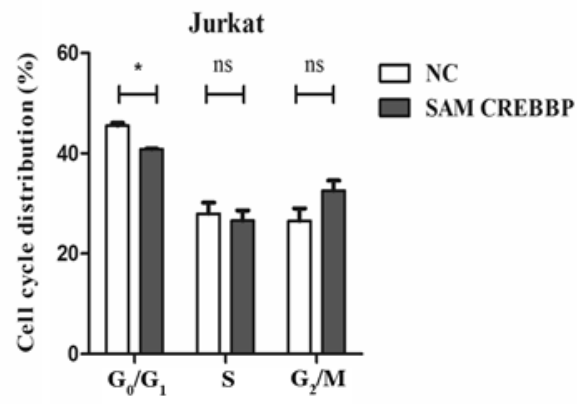

I

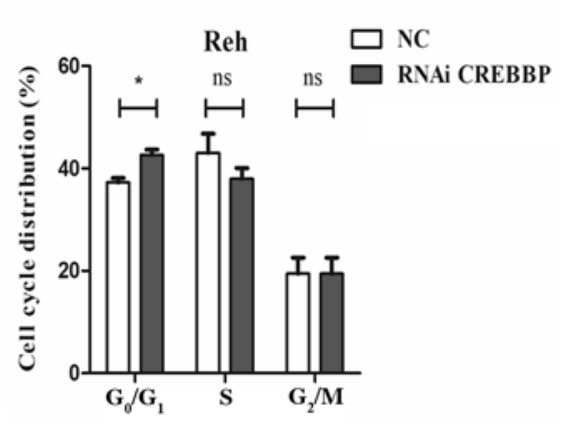

L

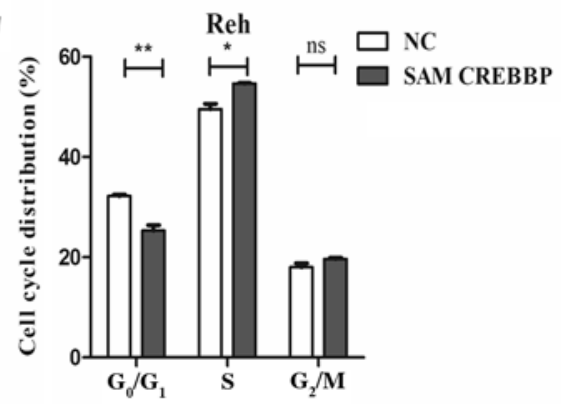

Figure 4. Effect of different CREBBP expression levels on Jurkat and Reh cell cycle distribution via flow cytometric analysis. Cell cycle distribution was analyzed using flow cytometry with PI staining. (A) RNAi CREBBP treated Jurkat cells. (B) RNAi control Jurkat cells. (C) Comparison of cycle distribution between RNAi CREBBP treated and control Jurkat cells. (D) SAM CREBBP treated Jurkat cells. (E) SAM control Jurkat cells. (F) Comparison of cycle distribution between SAM CREBBP treated and control Jurkat cells. (G) RNAi CREBBP treated Reh cells. (H) RNAi control Reh cells. (I) Comparison of cycle distribution between RNAi CREBBP treated and control Reh cells. (J) SAM CREBBP treated Reh cells. (K) SAM control Reh cells. (L) Comparison of cycle distribution between $\mathrm{SAM} C \mathrm{CREBBP}$ treated and control Reh cells. Data are presented as the mean \pm standard error of the mean $(\mathrm{n}=3)$. $\mathrm{P}<0.05$; ${ }^{* *} \mathrm{P}<0.01$. CREBBP, CREB-binding protein; RNAi, RNA interference; SAM, synergistic activation mediator; NC, negative control; ns, no significance; PI, propidium iodide.

expressed at the $\mathrm{G}_{1} / \mathrm{S}$ boundary (33), while E2F3b is expressed throughout the cell cycle and is associated with retinoblastoma protein $(\mathrm{Rb})$ and $\mathrm{Rb}$-associated proteins in a growth-arrested $\mathrm{G}_{0}$ state (34). A previous study reported that low E2F3a expression was associated with adverse outcomes in pediatric patients with ALL, and overexpression of E2F3a may enhance the sensitivity to DNR, which increased the proportion of leukemia cells in the $S$ and $G_{2} / M$ phases and accelerated cell proliferation (15). These findings are consistent with the biological manifestations of altered CREBBP expression as demonstrated in the present study, which suggested that CREBBP may influence E2F3a expression in leukemia cells. The present results also indicated that CREBBP and E2F3a co-localized in the nuclei and interacted with each other in Jurkat and Reh cells. Furthermore, E2F3a expression was identified to be consistent with CREBBP expression levels. Collectively, these results suggested that CREBBP and E2F3a may play a synergistic role in leukemia drug resistance. 

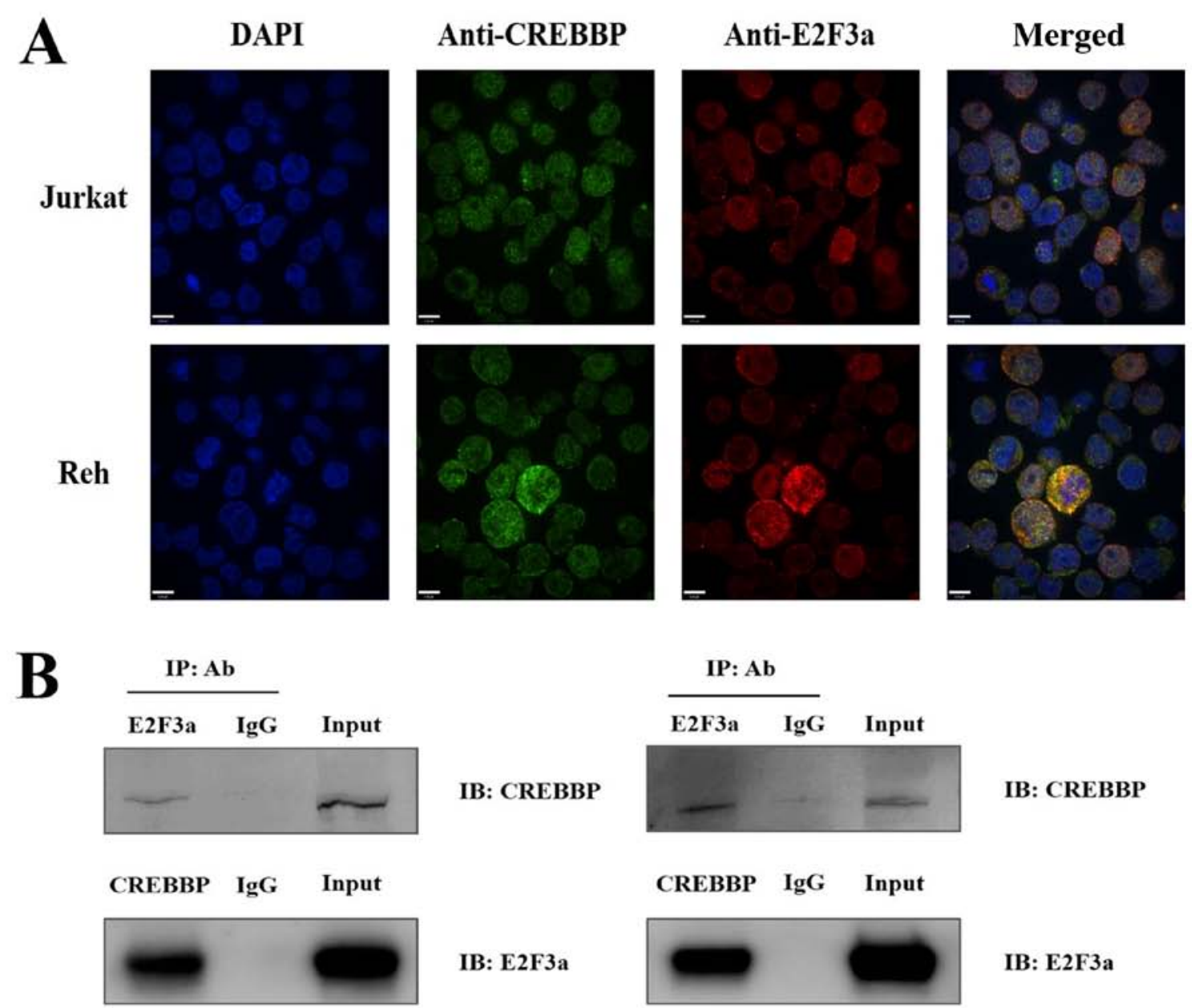

IB: CREBBP

IB: CREBBP

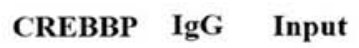

IB: E2F3a

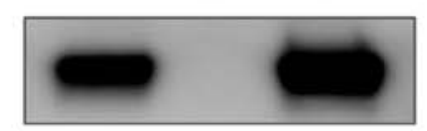

IB: E2F3a

Jurkat

Reh
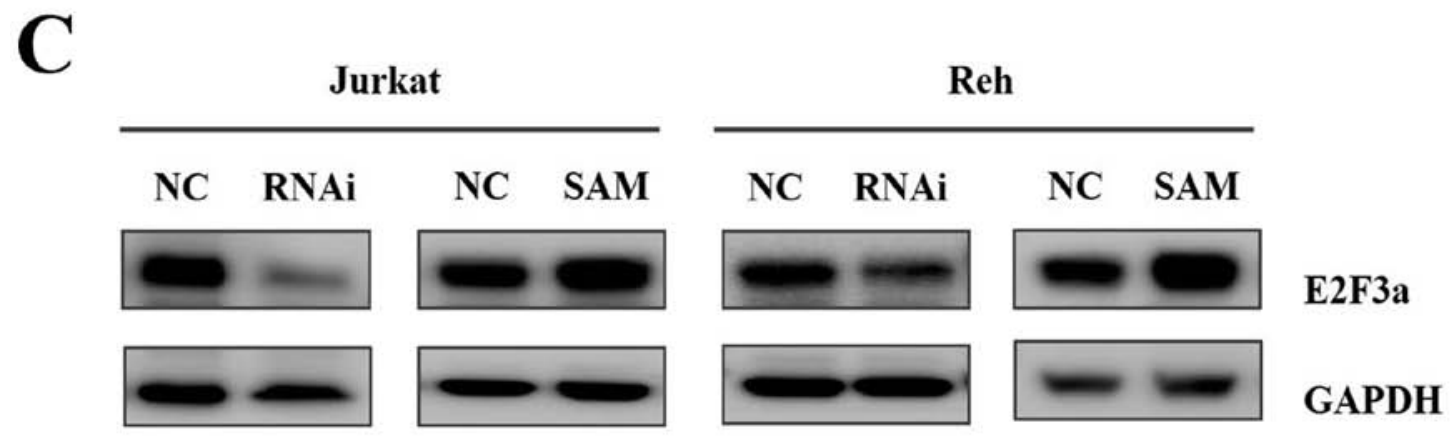

D
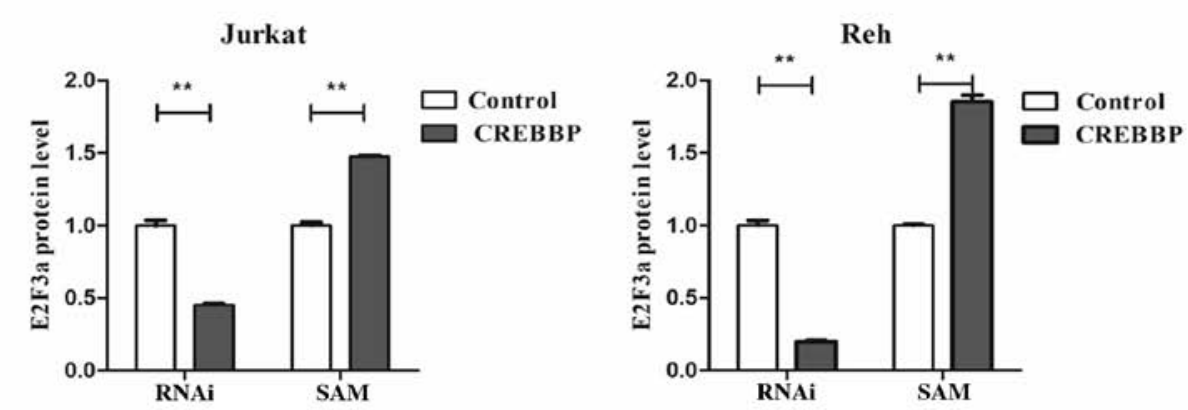

Figure 5. Co-localization and interaction of CREBBP and E2F3a in Jurkat and Reh cells. (A) CREBBP co-localized with E2F3a in the nuclei of Jurkat and Reh cells. Primary antibodies against CREBBP (green) and E2F3a (red) antibodies were used, and DAPI (blue) was used to stain the nuclei (scale bar, $6 \mu$ m; magnification, $\mathrm{x} 40$ ). (B) CREBBP interacts with E2F3a. Cell lysates were IP with mouse anti-CREBBP, mouse anti-E2F3 or mouse anti-IgG antibodies. IB was analyzed with rabbit anti-CREBBP or rabbit anti-E2F3 antibodies. IgG was used as the negative control, while the input (whole cell lysates) was used as the positive control. (C) Western blotting analysis of E2F3a protein expression in Jurkat and Reh cells following downregulation or overexpression of CREBBP. (D) Relative E2F3a protein expression in Jurkat and Reh cells following downregulation or overexpression of CREBBP. Data are presented as the mean \pm standard error of the mean $(n=3)$. ${ }^{* *} \mathrm{P}<0.01$. CREBBP, CREB-binding protein; IP, immunoprecipitated; Ab, antibody; IB, immunoblotting; RNAi, RNA interference; SAM, synergistic activation mediator; $\mathrm{NC}$, negative control. 


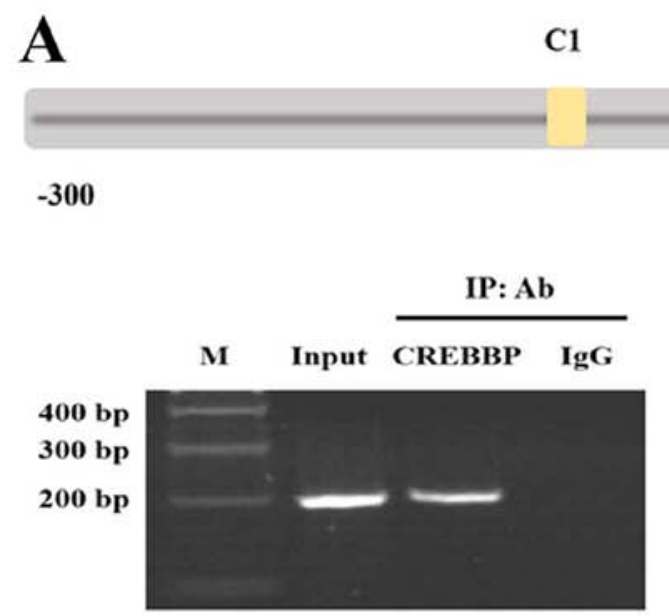

Jurkat

B

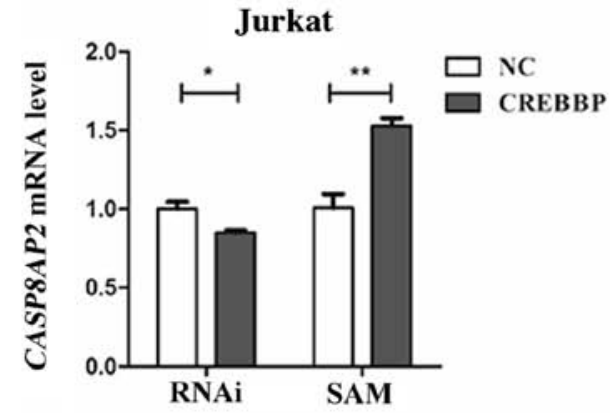

C

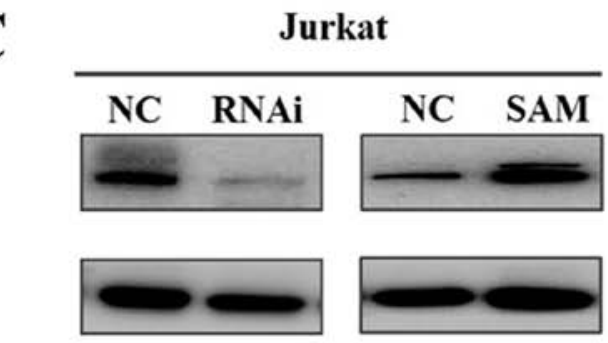

D

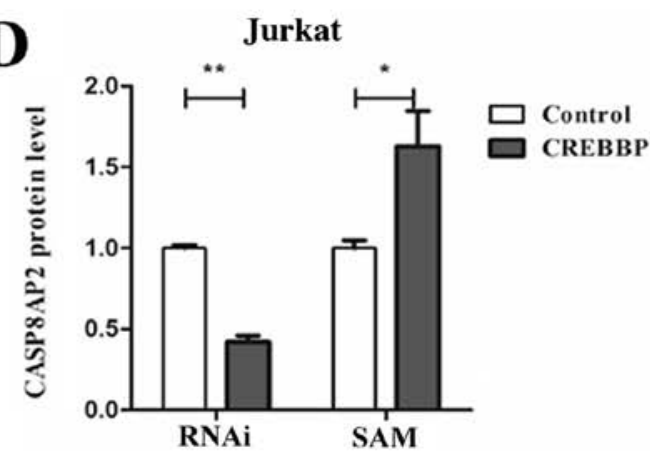

C2
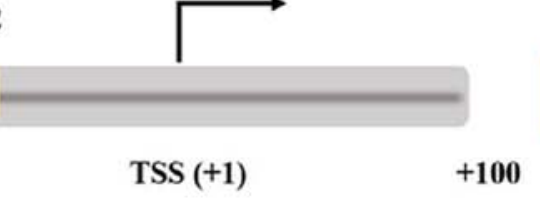

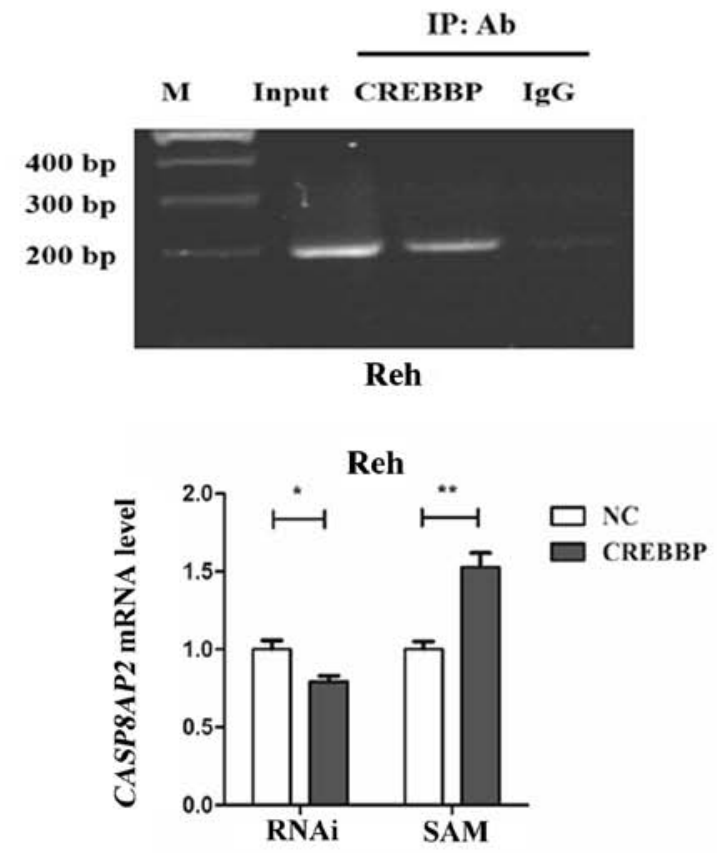

Reh
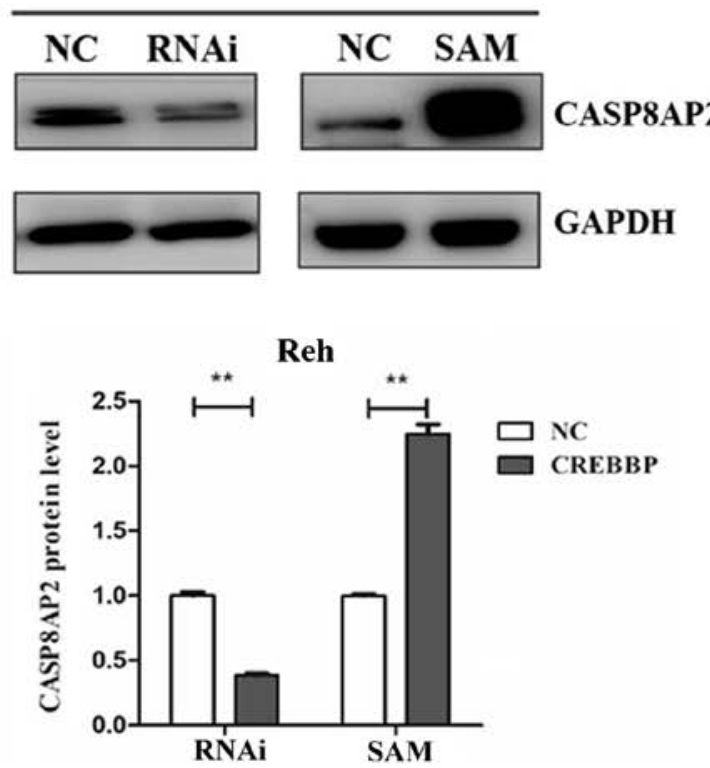

Figure 6. CASP8AP2 is a downstream target of CREBBP. (A) Schematic diagram of CASP8AP2 promoter fragments. The putative CREBBP binding sites are presented as yellow boxes: $\mathrm{C} 1(-120 \mathrm{bp})$ and C2 (-70 bp). TSS is indicated with an arrow. The numbers represent bp relative to TSS. (B) Chromatin immunoprecipitation assay identified CREBBP-binding sites in the CASP8AP2 promoter. The predicted binding sites were successfully amplified, from both the input DNA and the chromatin immunoprecipitated by anti-CREBBP antibody. Normal mouse IgG was used as the negative control. (C) Relative CASP8AP2 mRNA expression levels following downregulation or overexpression of CREBBP in Jurkat and Reh cells. Gene transcription levels were normalized to that of ABL and set to 1 in the control group. (D) Relative CASP8AP2 protein expression in Jurkat and Reh cells following downregulation or overexpression of CREBBP. Data are presented as the mean \pm standard error of the mean $(n=3) .{ }^{*} \mathrm{P}<0.05 ;{ }^{* *} \mathrm{P}<0.01$. CREBBP, CREB-binding protein; bp, base pair; TSS, transcription start site; M, DNA marker; IP, immunoprecipitated; Ab, antibody; NC, negative control; RNAi, RNA interference; SAM, synergistic activation mediator.

It has been reported that CASP8AP2 is a target gene of E2F3a, and low CASP8AP2 expression is associated with an unfavorable prognosis of pediatric patients with ALL $(15,35)$.
Furthermore, CASP8AP2 is a key protein involved in cell proliferation and $\mathrm{S}$ phase progression $(36,37)$. The present study demonstrated that CREBBP may bind to the promoter of 
CASP8AP2 and regulate gene transcription and protein expression. In addition, the present results indicated that CREBBP may serve as a scaffold to interpret molecular signals via its interaction with E2F3a in leukemia cells. Thus, CREBBP and E2F3a may synergistically control leukemia cells crossing the $\mathrm{G}_{1}$ phase and the regulation of target gene transcription, which plays a key role in $\mathrm{S}$ phase progression.

In conclusion, the results of the present study suggested that downregulation of CREBBP inhibited leukemia cell proliferation and caused cell cycle arrest at the $\mathrm{G}_{0} / \mathrm{G}_{1}$ phase. These results expand the current understanding of the molecular mechanisms associated with CREBBP insufficiency on chemotherapy resistance to DNR, and the association with adverse outcomes. Furthermore, CREBBP may interact with and regulate E2F3a to promote cell cycle progression, and serve as a scaffold to bind to the CASP8AP2 promoter as part of transcription regulation. It is still necessary to investigate the other regulatory pathways of CREBBP in ALL. In addition, further study targeting CREBBP in clinical intervention may lead to improved prognosis of ALL.

\section{Acknowledgements}

The authors would like to thank the Dr Hui Chen at the Beijing Key Laboratory of Pediatric Hematology Oncology, Hematology and Oncology Center, Beijing Children's Hospital, Capital Medical University (Beijing, China) for her assistance with the flow cytometric analysis.

\section{Funding}

The present study was funded by the National Natural Science Foundation of China (grant nos. 81300432 and 81300434), the Beijing Natural Science Foundation (grant no. 7192066) and the Major National Science and Technology Projects (grant no. 2017ZX09304029).

\section{Availability of data and materials}

The datasets used and/or analyzed during the present study are available from the corresponding authors upon reasonable request.

\section{Authors' contributions}

CG was the principal investigator who designed the study, performed the majority of the experiments and drafted the initial manuscript. SGL, WTL, ZXY, XXZ, TYX and ZPC performed some experiments. HYZ and ZGL designed the study and analyzed the data. All authors read and approved the final manuscript.

\section{Ethics approval and consent to participate}

Not applicable.

\section{Patient consent to participate}

Not applicable.

\section{Competing interests}

The authors declare that they have no competing interests.

\section{References}

1. Zhang J, Ding L, Holmfeldt L, Wu G, Heatley SL, Payne-Turner D, Easton J, Chen X, Wang J, Rusch M, et al: The genetic basis of early T-cell precursor acute lymphoblastic leukaemia. Nature 481: 157-163, 2012.

2. Holmfeldt L, Wei L, Diaz-Flores E, Walsh M, Zhang J, Ding L, Payne-Turner D, Churchman M, Andersson A, Chen SC, et al: The genomic landscape of hypodiploid acute lymphoblastic leukemia. Nat Genet 45: 242-52, 2013.

3. Paulsson K, Lilljebjörn H, Biloglav A, Olsson L, Rissler M, Castor A, Barbany G, Fogelstrand L, Nordgren A, Sjögren H, et al: The genomic landscape of high hyperdiploid childhood acute lymphoblastic leukemia. Nat Genet 47: 672-676, 2015.

4. Qian M, Zhang H, Kham SK, Liu S, Jiang C, Zhao X, Lu Y, Goodings C, Lin TN, Zhang R, et al: Whole-transcriptome sequencing identifies a distinct subtype of acute lymphoblastic leukemia with predominant genomic abnormalities of EP300 and CREBBP. Genome Res 27: 185-195, 2017.

5. Mullighan CG, Zhang J, Kasper LH, Lerach S, Payne-Turner D, Phillips LA, Heatley SL, Holmfeldt L, Collins-Underwood JR, Ma J, et al: CREBBP mutations in relapsed acute lymphoblastic leukaemia. Nature 471: 235-239, 2011.

6. Malinowska-Ozdowy K, Frech C, Schönegger A, Eckert C, Cazzaniga G, Stanulla M, zur Stadt U, Mecklenbräuker A, Schuster M, Kneidinger D, et al: KRAS and CREBBP mutations: A relapse-linked malicious liaison in childhood high hyperdiploid acute lymphoblastic leukemia. Leukemia 29: 1656-1667, 2015.

7. Horton SJ, Giotopoulos G, Yun H, Vohra S, Sheppard O, Bashford-Rogers R, Rashid M, Clipson A, Chan WI, Sasca D, et al: Early loss of Crebbp confers malignant stem cell properties on lymphoid progenitors. Nat Cell Biol 19: 1093-1104, 2017.

8. Gao C, Zhang RD, Liu SG, Zhao XX, Cui L, Yue ZX, Li WJ, Chen ZP, Li ZG, Rao Q, et al: Low CREBBP expression is associated with adverse long-term outcomes in paediatric acute lymphoblastic leukaemia. Eur J Haematol 99: 150-159, 2017.

9. Chan HM and La Thangue NB: p300/CBP proteins: HATs for transcriptional bridges and scaffolds. J Cell Sci 114: 2363-2373, 2001.

10. Yang XJ, Ogryzko VV, Nishikawa J, Howard BH and Nakatani Y: A p300/CBP-associated factor that competes with the adenoviral oncoprotein E1A. Nature 382: 319-324, 1996.

11. Gorgoulis VG, Zacharatos P, Mariatos G, Kotsinas A, Bouda M, Kletsas D, Asimacopoulos PJ, Agnantis N, Kittas C and Papavassiliou AG: Transcription factor E2F-1 acts as a growth-promoting factor and is associated with adverse prognosis in non-small cell lung carcinomas. J Pathol 198: 142-156, 2002.

12. DeGregori J: The genetics of the E2F family of transcription factors: Shared functions and unique roles. Biochim Biophys Acta 1602: 131-150, 2002.

13. Ross ME, Zhou X, Song G, Shurtleff SA, Girtman K, Williams WK, Liu HC, Mahfouz R, Raimondi SC, Lenny N, et al: Classification of pediatric acute lymphoblastic leukemia by gene expression profiling. Blood 102: 2951-2959, 2003.

14. Li Z, Zhang W, Wu M, Zhu S, Gao C, Sun L, Zhang R, Qiao N, Xue H, Hu Y, et al: Gene expression-based classification and regulatory networks of pediatric acute lymphoblastic leukemia. Blood 114: 4486-4493, 2009.

15. Liu FF, Wang KL, Deng LP, Liu X, Wu MY, Wang TY, Cui L and Li ZG: Transcription factor E2F3a regulates CASP8AP2 transcription and enhances sensitivity to chemotherapeutic drugs in acute lymphoblastic leukemia. Cancer Cell Int 18: 40, 2018.

16. Konermann S, Brigham MD, Trevino AE, Joung J, Abudayyeh OO, Barcena C, Hsu PD, Habib N, Gootenberg JS, Nishimasu $\mathrm{H}$, et al: Genome-scale transcriptional activation by an engineered CRISPR-Cas9 complex. Nature 517: 583-588, 2015.

17. Huang H, Zou X, Zhong L, Hou Y, Zhou J, Zhang Z, Xing X and Sun J: CRISPR/dCas9-mediated activation of multiple endogenous target genes directly converts human foreskin fibroblasts into Leydig-like cells. J Cell Mol Med 23: 6072-6084, 2019. 
18. Livak KJ and Schmittgen TD: Analysis of relative gene expression data using real-time quantitative PCR and the 2(-Delta Delta C(T)) method. Methods 25: 402-408, 2001.

19. Mei Y, Gao C, Wang K, Cui L, Li W, Zhao X, Liu F, Wu M, Deng G, Ding W, et al: Effect of microRNA-210 on prognosis and response to chemotherapeutic drugs in pediatric acute lymphoblastic leukemia. Cancer Sci 105: 463-472, 2014.

20. Toso $\mathrm{C}$ and Lindley C: Vinorelbine: A novel vinca alkaloid. Am J Health Syst Pharm 52: 1287-1304, 1995.

21. Fung MKL and Chan GC: Drug-induced amino acid deprivation as strategy for cancer therapy. J Hematol Oncol 10: 144, 2017.

22. Aubel-Sadron G and Londos-Gagliardi D: Daunorubicin and doxorubicin, anthracycline antibiotics, a physicochemical and biological review. Biochimie 66: 333-352, 1984.

23. Al-Aamri HM, Ku H, Irving HR, Tucci J, Meehan-Andrews T and Bradley C: Time dependent response of daunorubicin on cytotoxicity, cell cycle and DNA repair in acute lymphoblastic leukaemia. BMC Cancer 19: 179, 2019.

24. Frei E III and Sallan SE: Acute lymphoblastic leukemia: Treatment. Cancer 42 (2 Suppl): S828-S838, 1978

25. Garcia-Carpizo V, Ruiz-Llorente S, Sarmentero J, Graña-Castro O, Pisano DG and Barrero MJ: CREBBP/EP300 bromodomains are critical to sustain the GATA1/MYC regulatory axis in proliferation. Epigenetics Chromatin 11: 30, 2018.

26. Ait-Si-Ali S, Polesskaya A, Filleur S, Ferreira R, Duquet A, Robin P, Vervish A, Trouche D, Cabon F and Harel-Bellan A: $\mathrm{CBP} / \mathrm{p} 300$ histone acetyl-transferase activity is important for the G1/S transition. Oncogene 19: 2430-2437, 2000.

27. Dutta R, Tiu B and Sakamoto KM: CBP/p300 acetyltransferase activity in hematologic malignancies. Mol Genet Metab 119: 37-43, 2016.

28. Trouche D and Kouzarides T: E2F1 and E1A(12S) have a homologous activation domain regulated by RB and CBP. Proc Natl Acad Sci USA 93: 1439-1442, 1996.

29. Trouche D, Cook A and Kouzarides T: The CBP co-activator stimulates E2F1/DP1 activity. Nucleic Acids Res 24: 4139-4145, 1996.
30. Wang H, Larris B, Peiris TH, Zhang L, Le Lay J, Gao Y and Greenbaum LE: C/EBPbeta activates E2F-regulated genes in vivo via recruitment of the coactivator CREB-binding protein/P300. J Biol Chem 282: 24679-24688, 2007.

31. Martínez-Balbás MA, Bauer UM, Nielsen SJ, Brehm A and Kouzarides T: Regulation of E2F1 activity by acetylation. EMBO J 19: 662-671, 2000.

32. Marzio G, Wagener C, Gutierrez MI, Cartwright P, Helin K and Giacca M: E2F family members are differentially regulated by reversible acetylation. J Biol Chem 275: 10887-10892, 2000.

33. Leone G, DeGregori J, Yan Z, Jakoi L, Ishida S, Williams RS and Nevins JR: E2F3 activity is regulated during the cell cycle and is required for the induction of S phase. Genes Dev 12: 2120-2130, 1998.

34. Leone G, Nuckolls F, Ishida S, Adams M, Sears R, Jakoi L, Miron A and Nevins JR: Identification of a novel E2F3 product suggests a mechanism for determining specificity of repression by Rb proteins. Mol Cell Biol 20: 3626-3632, 2000.

35. Jiao Y, Cui L, Gao C, Li W, Zhao X, Liu S, Wu M, Deng G and $\mathrm{Li}$ Z: CASP8AP2 is a promising prognostic indicator in pediatric acute lymphoblastic leukemia. Leuk Res 36: 67-71, 2012.

36. Barcaroli D, Bongiorno-Borbone L, Terrinoni A, Hofmann TG, Rossi M, Knight RA, Matera AG, Melino G and De Laurenzi V: FLASH is required for histone transcription and S-phase progression. Proc Natl Acad Sci USA 103: 14808-14812, 2006.

37. De Cola A, Bongiorno-Borbone L, Bianchi E, Barcaroli D Carletti E, Knight RA, Di Ilio C, Melino G, Sette C and De Laurenzi V: FLASH is essential during early embryogenesis and cooperates with p73 to regulate histone gene transcription. Oncogene 31: 573-582, 2012

(i) $($ This work is licensed under a Creative Commons Attribution-NonCommercial-NoDerivatives 4.0 International (CC BY-NC-ND 4.0) License. 